\title{
Do Women Want to Lead? Gender Differences in Motivation and Values
}

\author{
Sarah Davies1, Henk Broekema², Marie Nordling3, Adrian Furnham ${ }^{1,4^{*}}$ \\ ${ }^{1}$ Research Department of Clinical, Educational and Health Psychology, University College London, London, UK \\ ${ }^{2}$ Advanced People Strategies Ltd., iCon Environmental Innovation Centre, Daventry, UK \\ ${ }^{3}$ PCL Tunbridge-Wells, Kent, UK \\ ${ }^{4}$ Norwegian Business School (BI), Olso, Norway \\ Email: *a.furnham@ucl.ac.uk
}

How to cite this paper: Davies, S., Broekema, H., Nordling, M., \& Furnham, A. (2017). Do Women Want to Lead? Gender Differences in Motivation and Values. Psychology, 8, 27-43.

http://dx.doi.org/10.4236/psych.2017.81003

Received: November 29, 2016

Accepted: December 27, 2016

Published: December 30, 2016

Copyright (C) 2017 by authors and Scientific Research Publishing Inc. This work is licensed under the Creative Commons Attribution International License (CC BY 4.0).

http://creativecommons.org/licenses/by/4.0/

\begin{abstract}
This paper considers the impact of gender differences in motivation and values on women's participation in management and senior executive roles, together with the extent to which women who do attain these roles resemble their male peers in terms of their motives and values. The results of a large, quantitative study using the Hogan Motives, Values and Preferences inventory $(\mathrm{N}=7571)$ are presented. These indicate that women do differ significantly from their male peers on 9 out of 10 motive and value scales but that the differences between senior women and their non-managerial female colleagues are less than those between senior men and their non-managerial male colleagues. As a result, key gender differences increase rather than decreasing at senior levels.
\end{abstract}

\section{Keywords}

Gender Differences, Motivation, Values

\section{Introduction}

Despite the fact that women in the US are awarded $57 \%$ of bachelor's degrees, $60 \%$ of master's degrees, $51 \%$ of doctor's degrees ${ }^{1}$ and they occupy $51 \%$ of all managerial and professional roles (Stone, 2013) and the majority of middle management roles (Cheung \& Halpern, 2010), their participation at senior executive level remains strikingly low. Women currently represent $4.8 \%$ of Fortune 500 CEOs (Catalyst Organization, 2014) and 14\% of Fortune 500 Executive committee members (Barsh \& Yee, 2012). Within the UK FTSE 100, only $4 \%$ of CEOs, $6.9 \%$ of executive directors and $15.6 \%$ of Executive committee members

${ }^{1}$ Source: US National Center for Education Statistics, 2011-2012 data. 
are women (Vinnicombe, Doldor, \& Turner, 2014).

The reasons for this continued low penetration of women into the C-suite are complex and have been extensively researched. A recent meta-analysis of primarily North American data over a period of nearly 50 years concluded that men and women do not differ in innate leadership effectiveness (Paustian-Underdahl, Walker, \& Woehr, 2014).

There is no strong evidence to suggest that men are more effective leaders than women. While there are potential differences in mean between men's and women's personality and style, these have been positively associated with leadership as often as negatively and there is some evidence to suggest that, at more senior levels, women's leadership style may converge with that of men (Eagly \& Carli, 2007; Judge, Bono, Ilies, \& Gerhardt, 2002).

\subsection{Obstacles to Women's Progression}

Research into the talent pipeline in the US found that women represent on average $53 \%$ of entry level employees and $40 \%$ of those at Manager level $^{2}$ (Barsh \& Yee, 2012) while other research puts the numbers at mid-management level even higher (Cheung \& Halpern, 2010). In the absence of compelling evidence to support the view that women are less capable than men at leading, what are the barriers that hinder their progress beyond this point?

The first is discrimination (Hultin, 2003; Ott, 1989; Smith, 2002). There is extensive anecdotal and empirical evidence of discrimination against women with regard to appointment to positions of leadership. Those women who want and apply for leadership roles are rejected more often than men which has two consequences: fewer women apply because they feel it is pointless and also it reinforces the idea that women neither want nor are able to take on important leadership jobs.

The second is gender stereotypes. Stereotypes lead to competing demands and a double bind for women leaders who are expected to fulfill conflicting role expectations as communal woman and agentic leader (Carli, 2001). Women who demonstrated assertive, directive leadership, strong agentic traits and masculine behaviour were negatively perceived as leaders (Pratch \& Jacobowitz, 1996) and evaluated more negatively than men displaying the same behaviour (Eagly, Makhijani, \& Klonsky, 1992), particularly in masculine domains (Heilman, Wallen, Fuchs, \& Tamkins, 2004).

Third, there is the work environment. The corporate workplace continues to be primarily based on the "total commitment model", with long hours and out of hours social activities (Lyness \& Thompson, 1997). These requirements are still easier for men to fulfill than women (O'Neil, Hopkins, \& Bilimoria, 2008): women spend more time dealing with domestic and family responsibilities even when they spend the same time as their partners at work (Lyness \& Thompson, 1997) and when they are the higher earners (Eagly \& Carli, 2007).

Within the workplace, norms of behaviour also tend to be male. Many men

${ }^{2}$ Based on a sample of 60 Fortune 500 or equivalent size US corporations. 
seem to enjoy competition while, particularly in mixed groups, many women do not like to be openly competitive (Niederle \& Vesterlund, 2007; van Vianen \& Fischer, 2002). Fewer women than men are attracted to overtly masculine cultures, characterised by competition, aggression and politics (Cabrera, 2007; Kleinjans, 2009).

Finally there is a lack of resource accumulation. The traditional career model follows a linear, hierarchical progression, as do typical male careers (Mainiero \& Sullivan, 2005). However, women are significantly more likely to take career breaks, which typically result in a loss of income and status, impeded career progression and difficulty reestablishing a career (Hewlett \& Luce, 2005). Women are also more likely than men to work part time and this, too, hinders career advancement (Hewlett \& Luce, 2005; Stone, 2013).

\subsection{Motivation, Values and Gender}

It has been suggested that self-selection may contribute to the current lack of women in senior roles, in that women may simply choose not to participate where they perceive they do not fit in (Peters, Ryan, Haslam, \& Fernandes, 2012). This raises the question as to whether women's motivation to reach senior roles plays a part: do women actually want to lead? In the McKinsey Wall Street Journal 2012 survey of 60 corporations of Fortune 500 or similar size, among entry and mid-level employees $74 \%$ of men and $69 \%$ of women wanted to advance to the next level but only $36 \%$ of men and $18 \%$ of women aspired to reach the C suite ${ }^{3}$ (Barsh \& Yee, 2012).

Hogan and his colleagues propose that individual behavior within groups is motivated by three universal needs: to be accepted by the group (to get along), to succeed, prevail and achieve status (to get ahead) and to find meaning (Hogan \& Blake, 1999; Hogan \& Chamorro-Premuzic, in press). The definition of values tends to focus on the concept of guiding life principles, which influence decision-making and behaviour (Ferssizidis et al., 2010; Parks \& Guay, 2009). Schwartz (1992) described values as fundamentally motivational and proposed ten universally distinct values representing "a continuum of motivation".

Eccles and her colleagues argue that gender differences in values, motivation and self-concept have causal influences on important outcomes such as occupational choice and performance (Eccles \& Wigfield, 2002; Wigfield, Battle, Keller, \& Eccles, 2002). It appears that women may be more or less attracted towards specific organisational cultures as a result of their motives, preferences and values. This suggests that self-selection may play a role in women's relative absence from senior management functions (van Vianen, \& Fischer, 2002).

A meta-analysis on the attributes men and women seek in jobs found these to be generally consistent with gender roles and stereotypes (Konrad, Ritchie, Lieb, \& Corrigall, 2000). Men more than women preferred opportunities for earnings, promotion, freedom, challenge, leadership, and power. Women more than men

${ }^{3}$ Agree/completely agree with the question: If anything were possible I would choose to advance to C-level of management. 
valued interpersonal relationships, helping others and also preferred good hours and an easy commute, which suggests a desire for greater flexibility and balance. However, rank order preferences between men and women were similar and the effect size of the differences was not large (Konrad et al., 2000).

In a study examining agentic and communal goals, the majority of women (60.2\%) rated communal goals (including intimacy, affiliation and altruism) as more important than agentic goals. The majority of men (61.6\%) rated agentic goals (including power, achievement and excitement) as more important. However, a substantial minority of both sexes showed a gender-atypical pattern (Pöhlmann, 2001, as cited in Diekman \& Eagly, 2008: p. 435).

In terms of values, in a series of studies integrating data from 127 samples across 70 countries, Schwartz and Rubel (2005) found that men attribute more importance than women to self-enhancement values (Power and Achievement) and to Stimulation, Hedonism and Self-direction values. Women attribute more importance than men to self-transcendence values (Benevolence and Universalism). In this study mean effect sizes were small: the meta-analytic effect sizes (average $\mathrm{d}$ weighted for sample size) were highest for Power $(\mathrm{d}=-.32)$ and Benevolence $(\mathrm{d}=.29)$. Age and culture accounted for more variance than gender.

Research into gender differences in power motivation has produced inconsistent findings. Some studies have found that men score significantly higher than women while others have reported no gender differences (Eagly, Karau, Miner, \& Johnson, 1994). A series of studies using samples from different populations (students and employees), cross-sectional and lagged designs and three different self-report power motivation scales found that men consistently reported significantly higher power motivation than women, with medium effect sizes ranging from $\mathrm{d}=.34$ to $\mathrm{d}=.60$ across the studies (Schuh et al., 2014). They also found support for a mediation model with power motivation mediating the relationship between gender and leadership role occupancy and concluded that this higher power motivation contributes to the higher proportion of male leaders (Schuh et al., 2014).

\subsection{Getting Along, Getting Ahead and Finding Meaning}

Using longitudinal data sampled from a repeated survey of US high school seniors, an analysis was carried out of adolescents' value orientations along three dimensions: compassion, materialism and meaning (Beutel \& Marini, 1995). This revealed substantial and persistent gender differences on all three measures. Women were consistently more likely than men to express concern and responsibility for the well-being of others (getting along) ( $p<.001)$, less likely to endorse materialism and competition values (getting ahead) $(p<.01)$ and more likely to stress the importance of finding purpose and meaning in life $(p<.05)$. There was evidence that gender differences in the 'finding meaning' dimension were reducing over time.

Hypothesis 1: Gender differences in motivation and values exist, although the effect sizes are likely to be small. Women are predicted to score higher than men 
on communal values, including altruism, affiliation and aesthetics but lower on power, commerce and science. The differences are predicted to be greatest for altruism (positively) and power (negatively).

Some studies have found that women who achieve senior management positions tend to have masculine personality profiles and to behave more like men (Hare, Koenigs, \& Hare, 1997; Wittenberg-Cox \& Maitland, 2008) and suggest that the role of organisational leadership may override stereotyped gender roles (Eagly \& Johnson, 1990; Heimovics \& Herman 1988).

Based on results from previous studies, Furnham and his colleagues predicted that women would score higher than men on Altruism, Affiliation and Aesthetics, while men would score higher on Power, Commerce and Science (Furnham, Hyde, \& Trickey, 2014). However, they found significant gender differences on 8 of the 10 values with men also scoring higher than women on Recognition and women higher than men on Hedonism.

A meta-analysis of job attribute preferences using 242 published and unpublished studies $(\mathrm{N}>638,000)$ found that, while most gender differences were consistent with gender roles and stereotypes, women in traditionally masculine occupations rated most masculine-typed job attributes at least as highly as men did (Konrad et al., 2000).

A Dutch study found evidence of gender differences in preference for masculine cultural values including competition, work pressure and effort $(p<.003)$ (van Vianen \& Fischer, 2002). These differences held among non-managerial employees, both career starters and tenured employees, but were not found among managers. However, they were unable to replicate this gender-managerial position interaction effect in a second study. Van Vianen and Fischer (2002) concluded that, once women reach management level, their preferences are more aligned to men's, not because women adjust their preferences but because the culture preferences of these women were already different from those of other women at the start of their careers. However, the cross-sectional nature of the data means that it is not possible to draw conclusions about causality.

Hypothesis 2: Gender differences in motivation and values reduce at successively higher levels of seniority. In particular, women at manager and director level are more motivated by stereotypically masculine factors such as power, commerce and science than are women in general.

\section{Method}

\subsection{Participants}

A database consisting of a total of 7571 participants from three different sources was accessed. Two of these sources were British based psychological consultancies licensed to administer the MVPI test. The first provided a complete data set of all subjects to whom it had administered the MVPI over a period of seven years. The second provided a smaller dataset consisting only of subjects with job classifications of "Directors" or "Managers and Professionals". In both cases, the majority of participants were employed as middle or senior managers or were 
assessed for managerial potential as part of an assessment centre or management development programme.

The third group (40 subjects) were approached personally by the authors and invited to complete the MVPI. These were all senior executives (22 men and 18 women) within the London (re)insurance market or associated with it.

Only records which provided the age and gender of the subject were included. Overall within the complete dataset, participants included 4548 males $(60.1 \%)$ and 3023 females (39.9\%) with ages ranging from 16 to 71 years with a median of 40.0 years and a mean of 39.6 years. 3433 (45.3\%) participants were classified as "Managers and professionals" and 225 (3\%) as Directors.

\subsection{Measures}

The Hogan and Hogan Motives, Values and Preferences Inventory (MVPI) was used as the basis for a quantitative analysis of motivation. This is a test of work values and preferences which relate to work motivation (Furnham, Hyde, \& Trickey, 2013) and which are associated with work related outcomes, including organisational fit, job satisfaction and occupational success (Hogan \& Hogan, 2010).

The MVPI is a validated, psychometrically sound assessment tool (Feltham \& Loan-Clarke, 2007 as cited in Hogan \& Hogan, 2010). Scores represent the extent to which people express an interest in certain activities that represent their values and motives. Scores demonstrate a high degree of stability over time with test-retest reliabilities ranging from .71 to .85 over a 3 -month period and from .70 to .83 over a $9-12$ month period (Hogan \& Hogan, 2010).

The MVPI (Hogan \& Hogan, 2010) has 200 items generating scores on 10 scales, which represent motives, values and preferences. A brief definition of each of these is provided in Table 1 .

\subsection{Procedure}

The majority of participants were tested over a period of several years at the request of a broad client base. In the case of the small sample approached directly, participants were asked to complete the questionnaire in return for a copy of their Hogan MVPI "Interpret" profile report and an optional feedback meeting with the authors.

The feedback provided to all participants is based on normed rather than raw score data: percentile ranks from a suitable comparison group using variables including job family, gender, age and ethnicity, which provide a context for interpreting the assessment scores (Hogan \& Hogan, 2010). For the purposes of this study the raw score data was used but, in the absence of individual information on occupation or job category, the job family selected was adopted as the basis for classifying participants as Directors, Managers or Non-managers. Clearly there are potential issues with this method. However, as job family is selected by the administrator supervising the testing, it was believed to be an 
Table 1. Summary of the 10 MVPI scales.

\begin{tabular}{|c|c|}
\hline & Definition \\
\hline Aesthetics & $\begin{array}{l}\text { Need for self-expression, a dedication to quality and excellence, } \\
\text { an interest in how things look, feel and sound. }\end{array}$ \\
\hline Affiliation & Needing and enjoying frequent and varied social contact and a social lifestyle. \\
\hline Altruism & Desire to help others, a concern for the welfare of the less fortunate, public service. \\
\hline Commerce & $\begin{array}{l}\text { Interest in earning money, realising profits, } \\
\text { finding new business opportunities, investments and financial planning. }\end{array}$ \\
\hline Hedonism & Pursuit of fun, excitement, pleasure, e.g., eating, drinking and entertainment. \\
\hline Power & Desire to succeed, make things happen, outperform the competition. \\
\hline Recognition & Desire to be known, seen, visible and famous, dreams of fame, high achievement. \\
\hline Science & $\begin{array}{l}\text { Being interested in science, comfortable with technology, preferring data } \\
\text { based-as opposed to intuitive-decisions, } \\
\text { and spending time learning how things work. }\end{array}$ \\
\hline Security & $\begin{array}{l}\text { A need for predictability, structure and efforts to avoid risk and } \\
\text { uncertainty and a lifestyle minimising errors and mistakes. }\end{array}$ \\
\hline Tradition & $\begin{array}{l}\text { A belief in and dedication to old-fashioned virtues: } \\
\text { family, church, thrift, hard work. }\end{array}$ \\
\hline
\end{tabular}

acceptable proxy.

It should be noted that the group size for Directors is significantly smaller than for the other two groups: 225 of which only 63 were women, compared with over 1000 in each of the other job/gender groups. The impact of this is discussed below.

\section{Results}

\subsection{Analysis of Variance}

The first step was to conduct a one-way between-groups analysis of variance (ANOVA) for all participants with the 10 MVPI value scales as the dependent variables and gender as the independent variable. The results are presented in Table 2.

Women scored significantly higher than men on Aesthetics, Affiliation, Altruism, Hedonistic and Security while men scored significantly higher than women on Commerce, Power, Recognition and Science.

Using Cohen's d (Cohen, 1988) to calculate effect sizes found no large effect sizes (>.8) and only Commerce showed a medium effect size (>.5), although Science approached this level. The effect sizes for Power and Altruism were both around .4. Hypothesis 1 that gender differences in motivation and values exist but that effect sizes tend to be small was partially supported: Power and Altruism did not show the largest differences although both are significant. It should be noted that views differ on the appropriate threshold values for effect sizes. A less conservative view would suggest that Commerce has a large effect size (>.5) and Altruism, Power and Science all show medium effect sizes (>.2). 
Table 2. Gender differences in the MVPI: All participants.

\begin{tabular}{ccccccccc}
\hline & \multicolumn{7}{c}{ Male } & \multicolumn{7}{c}{ Female } \\
\cline { 2 - 9 } & Mean & SD & Normed & Mean & SD & Normed & d & F \\
\hline Aesthetics & 33.19 & 7.733 & 48 & 34.88 & 8.159 & 58 & -.21 & $82.82^{* * *}$ \\
Affiliation & 49.19 & 5.726 & 36 & 50.10 & 5.157 & 46 & -.17 & $50.04^{* * *}$ \\
Altruism & 46.41 & 7.076 & 40 & 49.07 & 6.117 & 55 & -.40 & $284.34^{* * *}$ \\
Commerce & 44.57 & 6.699 & 36 & 40.76 & 6.598 & 58 & .57 & $594.97^{* * *}$ \\
Hedonism & 40.37 & 6.652 & 56 & 41.74 & 6.691 & 67 & -.21 & $76.52^{* * *}$ \\
Power & 47.39 & 6.865 & 48 & 44.52 & 7.159 & 38 & .41 & $306.74^{* * *}$ \\
Recognition & 40.92 & 7.645 & 53 & 39.61 & 7.083 & 49 & .18 & $56.04^{* * *}$ \\
Science & 41.43 & 8.192 & 49 & 37.52 & 8.057 & 37 & .48 & $419.44^{* * *}$ \\
Security & 37.81 & 7.635 & 40 & 38.60 & 7.723 & 44 & -.10 & $19.49^{* * *}$ \\
Tradition & 43.09 & 6.068 & 36 & 43.25 & 5.585 & 36 & $\mathrm{~ns}$ & 1.40 \\
\hline
\end{tabular}

Significance: ${ }^{* * *} p<.001$. Note: Normed scores based on Hogan global norms (Hogan Assessment Systems, 2011).

In order to examine how these results might vary with level of seniority, the ANOVA by gender was repeated on the two more senior job subsets: Firstly for the "Managers and Professionals" group and secondly for the Directors group. The ANOVA for "Managers and Professionals" produced an identical pattern of results to the overall ANOVA shown above, with all scales but Tradition showing significant differences in the predicted direction. Again, only Commerce showed a medium effect size (.58).

The results for the Directors group were more varied and are presented in Table 3.

According to Hypothesis 2, gender differences identified in the overall population were predicted to reduce at senior levels, particularly for stereotypically masculine factors such as power, commerce and science. For the Directors group, significant gender differences were found for only 6 out of the 10 MVPI scales.

Women scored higher than men on Aesthetics, Hedonism $(p<.05)$ and Altruism $(p<.001)$ while men scored higher than women on Science $(p<.01)$, Commerce and Power $(p<.001)$. There was no longer a significant gender difference for Affiliation, Recognition or Security within this group. However, contrary to expectations, effect sizes were larger than within the overall population: for Commerce these were now large (>.8) and for Altruism and Power, medium $(>.5)$, even using the more conservative standard. Hypothesis 2 was therefore not supported. On the contrary, the difference between men and women on masculine values, particularly Commerce and Power appears to be larger within this group than in the broader working population. It is also interesting that Affiliation, which is regarded as a stereotypically female value, showed no significant gender difference for this group.

In order to validate this result, a multivariate analysis of variance (MANOVA) 
Table 3. Gender differences in the MVPI: Directors.

\begin{tabular}{ccccccccc}
\hline & \multicolumn{7}{c}{ Male } & \multicolumn{7}{c}{ Female } \\
\cline { 2 - 9 } & Mean & SD & Normed & Mean & SD & Normed & d & F \\
\hline Aesthetics & 33.24 & 6.81 & 48 & 35.86 & 7.74 & 62 & -.36 & $6.19^{*}$ \\
Affiliation & 49.25 & 5.47 & 36 & 49.83 & 5.09 & 46 & ns & .53 \\
Altruism & 45.21 & 6.93 & 35 & 48.78 & 6.46 & 55 & -.53 & $12.49^{* * *}$ \\
Commerce & 46.61 & 5.53 & 69 & 41.48 & 6.80 & 36 & .83 & $34.20^{* * *}$ \\
Hedonism & 39.25 & 6.43 & 49 & 41.63 & 5.93 & 67 & -.39 & $6.52^{*}$ \\
Power & 48.75 & 5.73 & 59 & 44.68 & 6.16 & 38 & .68 & $21.87^{* * *}$ \\
Recognition & 39.58 & 7.21 & 49 & 38.65 & 6.71 & 43 & $\mathrm{~ns}$ & .78 \\
Science & 40.28 & 7.65 & 45 & 36.67 & 8.07 & 32 & .46 & $9.81^{* *}$ \\
Security & 36.30 & 7.09 & 30 & 34.65 & 6.22 & 25 & $\mathrm{~ns}$ & 2.63 \\
Tradition & 42.99 & 5.36 & 36 & 42.95 & 4.91 & 36 & $\mathrm{~ns}$ & .00 \\
\hline
\end{tabular}

Significance: ${ }^{*} p<.05,{ }^{* *} p<.01,{ }^{* *} p<.001$. Note: Normed scores based on Hogan global norms (Hogan Assessment Systems, 2011).

was conducted on the full dataset to examine the effects of gender, job code and their interaction on values, controlling for age. The 10 MVPI value scales were entered as dependent variables with gender and job code as independent variables and age as a covariate. This analysis found no significant gender-job code interaction effects, suggesting that gender differences in values do not vary significantly at different levels of seniority.

To understand how values might differ for men and women at different levels of seniority, a one-way ANOVA was then conducted within each gender separately, across the three job codes. For women, main effects were found for Commerce, Hedonism, Recognition $(p<.05)$ and Security $(p<.001)$. The main effect for Power approached significance $(\mathrm{p}=.055)$. For men, main effects were found for 7 out of 10 values: Power, Science, Security $(p<.05)$, Aesthetics, Altruism, Recognition $(p<.01)$ and Commerce $(p<.001)$. To establish where these differences lay, post-hoc analyses were carried out with Bonferroni adjustment to control the family wise error rate. The results of this analysis, showing only those values where significant results were found, are presented in $\mathrm{Ta}$ ble 4. Within this section, the Bonferroni adjusted p-values are quoted.

In summary, the results of the post-hoc analysis found that female Managers and Professionals scored higher than female Non-managers for Commerce and Power values $(p<.05)$ and lower for Hedonism $(p<.01)$ while Recognition was no longer significant. However, differences between women Directors and other women on these scales were not significant. The only value on which women Directors differed significantly from other women was Security where they scored lower $(p<.001)$. This suggests that female Directors are more comfortable taking risks both at a business level and with their personal lives than other women.

For men, Directors scored higher than all other men on Power $(p<.05)$ and 
Table 4. (a) Job group differences in the MVPI: Women; (b) Job group differences in the MVPI: Men.

(a)

\begin{tabular}{cccc}
\hline Dependent Variable & \multicolumn{2}{c}{ Job groups } & Mean Difference \\
\hline Commerce & Mgr & NMgr & $.63^{\star}$ \\
Hedonism & Mgr & NMgr & $-.73^{\star *}$ \\
Power & Mgr & NMgr & $.64^{\star}$ \\
Security & Dir & Mgr & $-3.81^{\star * \star}$ \\
Security & Dir & NMgr & $-4.22^{\star * *}$ \\
\hline
\end{tabular}

(b)

\begin{tabular}{cccc}
\hline Dependent Variable & \multicolumn{2}{c}{ Job groups } & Mean Difference \\
\hline Aesthetic & Mgr & NMgr & $-.77^{* *}$ \\
Altruism & Dir & NMgr & $-1.56^{\star}$ \\
Altruism & Mgr & NMgr & $-.64^{\star *}$ \\
Commerce & Dir & Mgr & $1.76^{* *}$ \\
Commerce & Dir & NMgr & $2.43^{* *}$ \\
Commerce & Mgr & NMgr & $.67^{* *}$ \\
Power & Dir & Mgr & $1.35^{\star}$ \\
Power & Dir & NMgr & $1.46^{*}$ \\
Recognition & Dir & NMgr & $-1.63^{*}$ \\
Security & Dir & NMgr & $-1.64^{*}$ \\
\hline
\end{tabular}

Dir $=$ Director, Mgr = Managers and Professionals, N/Mgr $=$ Non-manager. Mean differences are the difference in means between the job groups (positive values mean the first group is higher, negative mean the second group is higher). Significance: ${ }^{\star} p<.05,{ }^{* *} p<.01,{ }^{* * *} p<.001$.

Commerce $(p<.01)$. They also scored lower than Non-managers on Recognition, Security and Altruism $(p<.05)$, although their scores were not significantly different from those of Managers and Professionals. Managers and Professionals scored higher than Non-managers on Commerce $(p<.001)$ and lower on Aesthetics and Altruism $(p<.01)$. Science was no longer significant. Thus, in this analysis, Commerce values (positively) and Altruism (negatively) predict seniority among men, with Directors also distinguished by their higher Power motivation and (compared with Non-managers) their lower need for Recognition and Security.

\subsection{Factor Analysis}

To examine these conclusions further, a principal components factor analysis was conducted on the correlations of the 10 MVPI scales. Three factors were extracted with eigenvalues greater than 1.00 and these were subject to orthogonal (Varimax) rotation. The three factors accounted for a total of $55.8 \%$ of the variance. The results of the factor analysis are shown in Table 5.

The three factors differ from those identified in the MVPI manual (Hogan \& Hogan, 2010) but are consistent with other recent studies (Furnham et al., 2013; 
Table 5. Factor analysis of the 10 Scale MVPI.

\begin{tabular}{cccc}
\hline & \multicolumn{3}{c}{ Factors } \\
\cline { 2 - 4 } & 1 & 2 & 3 \\
\hline Commerce & .83 & .04 & -.11 \\
Power & .76 & .33 & .02 \\
Science & .55 & -.17 & .23 \\
Recognition & .53 & .52 & .04 \\
Affiliation & .05 & .72 & .21 \\
Hedonism & .17 & .68 & .00 \\
Security & .33 & -.48 & .26 \\
Altruism & -.03 & .08 & .84 \\
Tradition & .22 & -.29 & .71 \\
Aesthetics & -.03 & .29 & .60 \\
Eigenvalue & 2.41 & 1.73 & 1.44 \\
Variance \% & 24.14 & 17.26 & 14.39
\end{tabular}

Only factor loadings greater than .40 (highlighted in bold) were considered to contribute significantly.

Furnham et al., 2014), where they are described respectively as Enterprising, Social and Tradition.

An ANOVA was then conducted using the three factors as dependent variables and gender as the independent variable. The results are presented in Table 6 .

Significant gender differences $(p<.001)$ were found for factors Enterprising and Tradition but not for Social. Men scored higher than women on Enterprising while women scored higher on Tradition. This analysis was repeated for each of the three job subsets in turn but the results were consistent with the ANOVA for all participants.

\subsection{Discriminant Analysis}

Finally, a discriminant analysis was conducted to identify which of the 10 MVPI scales best predicted gender. The log determinants were similar but the Box's $M$ test indicated that the assumption of equality of covariance matrices was violated. However, given the very large sample size, this problem is not regarded as serious. The results of the analysis are presented in Table 7.

A canonical correlation of .415 suggests that the model accounts for $17.2 \%$ of the between-group variability, with four variables showing discriminate loadings which achieve significance $(>.30)$. These presented a similar pattern to the previous analyses, with Commerce, Science and Power best predicting male group members and Altruism best predicting female group members.

As a predictor of gender, the model did not score particularly well, however. The cross-validated classification showed that overall $69.5 \%$ were correctly classified. While $81.9 \%$ of men were classified correctly, the model performed little better than chance $(51 \%)$ on classifying women. 
Table 6. Gender differences for the MVPI analysed by factors.

\begin{tabular}{|c|c|c|c|c|c|c|}
\hline & \multicolumn{2}{|c|}{ Male } & \multicolumn{2}{|c|}{ Female } & \multirow[b]{2}{*}{$\mathrm{d}$} & \multirow[b]{2}{*}{$\mathrm{F}$} \\
\hline & Mean & SD & Mean & SD & & \\
\hline Enterprising & 43.58 & 5.07 & 40.60 & 5.03 & .59 & $628.95^{* * *}$ \\
\hline Social & 23.17 & 4.27 & 23.21 & 4.22 & ns & .21 \\
\hline Tradition & 40.90 & 5.12 & 42.40 & 4.84 & -.30 & $163.39^{* * *}$ \\
\hline
\end{tabular}

Significance: ${ }^{* * *} p<.001$.

Table 7. Discriminant analysis structure matrix.

\begin{tabular}{cc}
\hline & Factor 1 \\
Commerce & -.62 \\
Science & -.52 \\
Power & -.44 \\
Altruism & .43 \\
Aesthetics & .23 \\
Hedonism & .22 \\
Recognition & -.19 \\
Affiliation & .18 \\
Security & .11 \\
Tradition & .03
\end{tabular}

\section{Discussion}

The results of this study were consistent with previous research. In general, men score higher than women on Commerce, Power and Science and women score higher than men on Altruism, Affiliation and Aesthetics. Hypothesis 1 was only partially supported as Power and Altruism showed smaller differences than Commerce and Science.

This study also found significant gender differences in Recognition (men higher) and in Hedonism and Security (women higher). Other studies using the MVPI have found comparable results for Hedonism and Recognition (Furnham et al., 2014) and some studies using different instruments have found women to have higher security motivations (Chow \& Ngo, 2002).

Effect sizes in general were small, with only Commerce reaching the medium level, although effect sizes for Science, Power and Altruism all exceeded .40. Other studies into power motivation have found effects sizes ranging from $\mathrm{d}$ $=.34$ to $\mathrm{d}=.60$ and have classified these as medium (Schuh et al., 2014). These are consistent with this study's findings for Power $(\mathrm{d}=.41)$. Overall, this study's findings of effects sizes which are mostly in excess of .20 compare favourably with other studies of psychological gender differences (Hyde \& Plant, 1995).

A discriminant analysis also identified Commerce, Science, Power (for men) and Altruism (for women) as the most important values in distinguishing be- 
tween the male and female groups. Consistent with research previously cited (Diekman \& Eagly, 2008; Pratch \& Jacobowitz, 1996), men were found to be motivated more by agentic and scientific values (Power, Commerce and Science) and women more by communal values (including Altruism).

Contrary to Hypothesis 2, no significant gender-job group interaction was found, suggesting that gender differences do not vary significantly across the three job subsets. This may be because, as a relatively expensive psychometric instrument, the Hogan MVPI is generally only used on relatively senior employees or on those being assessed for managerial potential. As a result, the distinction between the two groups may not be clear enough to show the predicted differences.

The "Directors" group, while only representing 3\% of the total population, showed a somewhat different pattern of results. For this group, only six of the value scales showed significant gender differences. Commerce, Power, Science and Altruism remain the most significant factors with men scoring higher on the first three. Women continue to score significantly higher on Altruism as well as Aesthetics and Hedonism. Gender differences for Affiliation, Recognition and Security were no longer significant at this level.

What is perhaps most striking in these results is that the effect sizes for gender differences in Commerce, Power and Altruism in particular, increased rather than reducing for this group. Thus it appears that, on these measures, alignment of values with gender stereotypes is stronger at this more senior level. However, this is not because senior women are less motivated by Power and Commerce than other women. In fact, women's scores for Power and Commerce are significantly higher among Managers and Professionals (although not among Directors) than among Non-managers $(p<.05)$ so that Hypothesis 2 is partially supported. However, the differential among men on these values at higher levels of seniority also increases and by a larger factor than for women. As a consequence, the gap between men and women increases at higher levels of seniority, contrary to Hypothesis 2. Overall, the results show greater evidence of differences among men than among women at the three levels of seniority.

As this study does not use longitudinal data, it is not possible to conclude that men's or women's values change as they reach higher levels of seniority. The results suggest that those women who reach the most senior levels within organisations are not necessarily those whose values and preferences are more similar to men's from the start of their careers as Van Vianen and Fischer (2002) concluded. However, nor have they necessarily changed their preferences in line with the dominant male culture.

It appears that these women retain a set of values and preferences, consistent with gender roles, which are distinct from those of their male peers. These women have all made a conscious choice to enter the business world and have therefore found a means of reconciling their motives and values with the prevailing business culture and of navigating successfully "through the labyrinth", as noted by Eagly and Carli (2007). 
There is scope for further research into the mechanisms which enable these women to achieve senior roles, using data from the Hogan Personality Inventory (HPI) and the Hogan Development Survey (HDS) as well as the MVPI. As an example, high Hedonism (MVPI) is associated with high Sociability and low Prudence (HPI) and with high Sceptical and high Mischievous (HDS). This profile would indicate an ability to see through organisational politics and use charm to persuade. This might suggest that such women succeed due to a greater willingness and ability to engage in social and political games.

The remaining results of the factor analysis show a strong gender distinction. Men scored significantly higher than women on Enterprising, which includes Commerce, Power, Science and Recognition, with a medium effect size $(d=.59)$. Women scored higher than men on Tradition, which includes Altruism, Tradition and Aesthetics, although the effect size is smaller $(\mathrm{d}=-.30)$. This holds across all job groups. This suggests that men are more attracted than women to enterprising and entrepreneurial cultures while women are more attracted than men to traditional settings, as also concluded by Furnham et al., (2014). While we cannot draw firm conclusions about causality, the implications of this finding are that the socialisation of women tends to attract them to roles which align with values of Altruism (helping others, developing staff and providing good customer service), Tradition (respect for traditional values, stability and loyalty) and Aesthetics (intuitive, valuing creativity and aesthetic values).

This study inevitably has a number of limitations. While it includes a very large number of participants and a reasonable gender balance, it would have been helpful to have specific information relating to level of seniority to validate the use of the job groups. For further research it would be helpful to have additional data on other potential confounding factors, including sector, job history, job satisfaction and performance. The study also relied on a single self-report instrument for the collection of quantitative data and is therefore potentially subject to common methods bias. Finally, as noted above, the MVPI is predominantly used with managerial staff or those being assessed for managerial roles and consequently the dataset is likely to be more homogeneous than the broader working population.

\section{References}

Barsh, J., \& Yee, L. (2012). Unlocking the Full Potential of Women at Work. McKinsey \& Company/Wall Street Journal. http://www.mckinsey.com/client_service/organization/latest_thinking/women_at_wor $\underline{\mathrm{k}}$

Beutel, A. M., \& Marini, M. M. (1995). Gender and Values. American Sociological Review, 60, 436-448. https://doi.org/10.2307/2096423

Cabrera, E. F. (2007). Opting Out and Opting In: Understanding the Complexities of Women's Career Transitions. Career Development International, 12, 218-237. https://doi.org/10.1108/13620430710745872

Carli, L. L. (2001). Gender and Social Influence. Journal of Social Issues, 57, 725-741. https://doi.org/10.1111/0022-4537.00238 
Catalyst Organization (2014). Women CEOs of the Fortune 1000. http://catalyst.org/knowledge/women-ceos-fortune-1000

Cheung, F. M., \& Halpern, D. F. (2010). Women at the Top: Powerful Leaders Define Success as Work + Family in a Culture of Gender. American Psychologist, 65, 182. https://doi.org/10.1037/a0017309

Chow, I. H. S., \& Ngo, H. Y. (2002). Gender Differences in Job Attribute Preferences and Job Choice of University Students in China. Journal of Applied Business Research, 18, $15-26$.

Cohen, J. (1988). Statistical Power Analysis for the Behavioral Sciences (2nd ed.). Hillsdale, NJ: Lawrence Earlbaum Associates.

Diekman, A. B., \& Eagly, A. H. (2008). Of Men, Women, and Motivation: A Role Congruity Account. In J. Y. Shah \& W. L. Gardner (Eds.), Handbook of Motivation Science (pp. 434-447). New York: Guilford.

Eagly, A. H., \& Carli, L. L. (2007). Through the Labyrinth: The Truth about How Women Become Leaders. Boston, MA: Harvard Business Press.

Eagly, A. H., \& Johnson, B. T. (1990). Gender and Leadership Style: A Meta-Analysis. Psychological Bulletin, 108, 233-256. https://doi.org/10.1037/0033-2909.108.2.233

Eagly, A. H., Karau, S. J., Miner, J. B., \& Johnson, B. T. (1994). Gender and Motivation to Manage in Hierarchic Organizations: A Meta-Analysis. The Leadership Quarterly, 5, 135-159. https://doi.org/10.1016/1048-9843(94)90025-6

Eagly, A. H., Makhijani, M. G., \& Klonsky, B. G. (1992). Gender and the Evaluation of LEADERS: A META-ANAlysis. Psychological Bulletin, 111, 3-22. https://doi.org/10.1037/0033-2909.111.1.3

Eccles, J. S., \& Wigfield, A. (2002). Motivational Beliefs, Values, and Goals. Annual review of psychology, 53, 109-132. https://doi.org/10.1146/annurev.psych.53.100901.135153

Ferssizidis, P., Adams, L. M., Kashdan, T. B., Plummer, C., Mishra, A., \& Ciarrochi, J. (2010). Motivation for and Commitment to Social Values: The Roles of Age and Gender. Motivation and Emotion, 34, 354-362. https://doi.org/10.1007/s11031-010-9187-4

Furnham, A., Hyde, G., \& Trickey, G. (2013). The Values of Work Success. Personality and Individual Differences, 55, 485-489. https://doi.org/10.1016/j.paid.2013.04.016

Furnham, A., Hyde, G., \& Trickey, G. (2014). The Dark Side of Career Preference: Dark Side Traits, Motives, and Values. Journal of Applied Social Psychology, 44, 106-114. https://doi.org/10.1111/jasp.12205

Hare, A. P., Koenigs, R. J., \& Hare, S. E. (1997). Perceptions of Observed and Model Values of Male and Female Managers. Journal of Organizational Behavior, 18, 437-447. https://doi.org/10.1002/(SICI)1099-1379(199709)18:5<437::AID-JOB806>3.0.CO;2-0

Heilman, M. E., Wallen, A. S., Fuchs, D., \& Tamkins, M. M. (2004). Penalties for Success: Reactions to Women Who Succeed at Male Gender-Typed Tasks. Journal of Applied Psychology, 89, 416-427. https://doi.org/10.1037/0021-9010.89.3.416

Heimovics, R. D., \& Herman, R. D. (1988). Gender and the Attributions of Chief Executive Responsibility for Successful or Unsuccessful Organizational Outcomes. Sex Roles, 18, 623-635. https://doi.org/10.1007/BF00287965

Hewlett, S. A., \& Luce, C. B. (2005). Off-Ramps and On-Ramps: Keeping Talented Women on the Road to Success. Harvard Business Review, 83, 43-54.

Hogan Assessment Systems (2011). Hogan Personality Inventory, Hogan Development Survey and Motives, Values, Preferences Inventory Global Norms. Documentation of Normative Data, Tulsa, OK: Author.

Hogan, R., \& Blake, R. (1999). John Holland's Vocational Typology and Personality 
Theory. Journal of Vocational Behavior, 55, 41-56.

https://doi.org/10.1006/jvbe.1999.1696

Hogan, R., \& Hogan, J. (2010). Motives, Values, and Preferences Inventory Manual. 2010 Administrative and Norming Updates, Tulsa, OK: Hogan Assessment Systems.

Hultin, M. (2003). Some Take the Glass Escalator, Some Hit the Glass Ceiling? Career Consequences of Occupational Sex Segregation. Work and Occupations, 30, 30-61. https://doi.org/10.1177/0730888402239326

Hyde, J. S., \& Plant, E. A. (1995). Magnitude of Psychological Gender Differences: Another Side to the Story. American Psychologist, 50, 159-161. https://doi.org/10.1037/0003-066X.50.3.159

Judge, T. A., Bono, J. E., Ilies, R., \& Gerhardt, M. W. (2002). Personality and Leadership: a Qualitative and Quantitative Review. Journal of Applied Psychology, 87, 765-780. https://doi.org/10.1037/0021-9010.87.4.765

Kleinjans, K. J. (2009). Do Gender Differences in Preferences for Competition Matter for Occupational Expectations? Journal of Economic Psychology, 30, 701-710.

https://doi.org/10.1016/j.joep.2009.03.006

Konrad, A. M., Ritchie Jr, J. E., Lieb, P., \& Corrigall, E. (2000). Sex Differences and Similarities in Job Attribute Preferences: A Meta-Analysis. Psychological Bulletin, 126, 593-641. https://doi.org/10.1037/0033-2909.126.4.593

Lyness, K. S., \& Thompson, D. E. (1997). Above the Glass Ceiling? A Comparison of Matched Samples of Female and Male Executives. Journal of Applied Psychology, 82, 359-375. https://doi.org/10.1037/0021-9010.82.3.359

Mainiero, L. A., \& Sullivan, S. E. (2005). Kaleidoscope Careers: An Alternate Explanation for the "Opt-Out" Revolution. The Academy of Management Executive, 19, 106-123. https://doi.org/10.5465/ame.2005.15841962

Niederle, M., \& Vesterlund, L. (2007). Do Women Shy away from Competition? Do Men Compete too Much? The Quarterly Journal of Economics, 122, 1067-1102. https://doi.org/10.1162/qjec.122.3.1067

O’Neil, D. A., Hopkins, M. M., \& Bilimoria, D. (2008). Women's Careers at the Start of the 21st Century: Patterns and Paradoxes. Journal of Business Ethics, 80, 727-743. https://doi.org/10.1007/s10551-007-9465-6

Ott, E. M. (1989). Effects of the Male-Female Ratio at Work. Psychology of Women Quarterly, 13, 41-57. https://doi.org/10.1111/j.1471-6402.1989.tb00984.x

Parks, L., \& Guay, R. P. (2009). Personality, Values, and Motivation. Personality and Individual Differences, 47, 675-684. https://doi.org/10.1016/j.paid.2009.06.002

Paustian-Underdahl, S. C., Walker, L. S., \& Woehr, D. J. (2014). Gender and Perceptions of Leadership Effectiveness: A Meta-Analysis of Contextual Moderators. Journal of Applied Psychology, 99, 1129-1145. https://doi.org/10.1037/a0036751

Peters, K., Ryan, M., Haslam, S. A., \& Fernandes, H. (2012). To Belong or Not to Belong: Evidence That Women'S Occupational Disidentification Is Promoted by Lack of Fit with Masculine Occupational Prototypes. Journal of Personnel Psychology, 11, 148158. https://doi.org/10.1027/1866-5888/a000067

Pratch, L., \& Jacobowitz, J. (1996). Gender, Motivation, and Coping in the Evaluation of Leadership Effectiveness. Consulting Psychology Journal: Practice and Research, 48, 203-218. https://doi.org/10.1037/1061-4087.48.4.203

Schuh, S. C., Bark, A. S. H., Van Quaquebeke, N., Hossiep, R., Frieg, P., \& Van Dick, R. (2014). Gender Differences in Leadership Role Occupancy: The Mediating Role of Power Motivation. Journal of Business Ethics, 120, 363-379.

https://doi.org/10.1007/s10551-013-1663-9 
Schwartz, S. H. (1992). Universals in the Content and Structure of Values: Theory and Empirical Tests in 20 Countries. In M. Zanna (Ed.), Advances in Experimental Social Psychology (Vol. 25, pp. 1-65). New York: Academic Press.

Schwartz, S. H., \& Rubel, T. (2005). Sex Differences in Value Priorities: Cross-Cultural and Multimethod Studies. Journal of Personality and Social Psychology, 89, 1010-1028. https://doi.org/10.1037/0022-3514.89.6.1010

Smith, R. A. (2002). Race, Gender, and Authority in the Workplace: Theory and Research. Annual Review of Sociology, 28, 509-542. https://doi.org/10.1146/annurev.soc.28.110601.141048

Stone, P. (2013). "Opting out": Challenging Stereotypes and Creating Real Options for Women in the Professions. Harvard Business School Faculty Conferences Website. http://www.hbs.edu/faculty/conferences/2013-w50-research-symposium/Documents/st one.pdf

Van Vianen, A. E., \& Fischer, A. H. (2002). Illuminating the Glass Ceiling: The Role of Organizational Culture Preferences. Journal of Occupational and Organizational Psychology, 75, 315-337. https://doi.org/10.1348/096317902320369730

Vinnicombe, S., Doldor, E., \& Turner, C. (2014). The Female FTSE Board Report 2014: Crossing the Finish Line. Cranfield University School of Management Website.

Wittenberg-Cox, A., \& Maitland, A. (2008). Why Women Mean Business: Understanding the Emergence of Our Next Economic Revolution. Chichester: John Wiley \& Sons.

\section{Submit or recommend next manuscript to SCIRP and we will provide best service for you:}

Accepting pre-submission inquiries through Email, Facebook, LinkedIn, Twitter, etc. A wide selection of journals (inclusive of 9 subjects, more than 200 journals) Providing 24-hour high-quality service User-friendly online submission system Fair and swift peer-review system Efficient typesetting and proofreading procedure Display of the result of downloads and visits, as well as the number of cited articles Maximum dissemination of your research work

Submit your manuscript at: http://papersubmission.scirp.org/

Or contact psych@scirp.org 